\title{
Electrokinetic-enhanced Transport of Lactate-Modified Nanoscale Iron Particles for Degradation of Dinitrotoluene in Clayey Soils
}

\author{
Krishna R. Reddy*, Professor \\ Department of Civil and Materials Engineering, University of Illinois at Chicago, \\ 842 West Taylor Street, Chicago, Illinois 60607, USA \\ e-mail: kreddy@uic.edu \\ (*Corresponding author)
}

Kenneth Darko-Kagya, Graduate Research Assistant

Department of Civil and Materials Engineering, University of Illinois at Chicago, 842 West Taylor Street, Chicago, Illinois 60607, USA

e-mail: kdarko2@uic.edu

8

Department of Chemical Engineering, University of Vigo, University Campus, Building Fundicion, 36310 Vigo, Spain e-mail: claudio@uvigo.es 


\section{Electrokinetic-enhanced Transport of Lactate-Modified Nanoscale Iron} Particles for Degradation of Dinitrotoluene in Clayey Soils

4 Abstract

5 This study investigated the transport and reactivity of bare nanoscale iron particles (NIP) and

6 lactate modified NIP (LM-NIP) in low permeability clayey soils contaminated with

7 dinitrotoluene (DNT) under applied electric potential. Bench-scale electrokinetic experiments

8 were performed at constant voltage gradient $(1 \mathrm{VDC} / \mathrm{cm})$ with DNT spiked kaolinite at a

9 concentration of $920 \mathrm{mg} / \mathrm{kg}$. A cylindrical Plexiglas cell (3.81 inner diameter, $13.5 \mathrm{~cm}$ length)

10 specially designed for this study was used. NIP or LM-NIP at a concentration of $4 \mathrm{~g} / \mathrm{L}$ was

11 injected at location $3 \mathrm{~cm}$ from the anode. Aluminum lactate 10\% $(\mathrm{w} / \mathrm{w})$ was used as modifier for

12 LM-NIP. The results showed 41 to $65 \%$ of DNT degradation in the soil near the anode, while it

13 was lower at 30 to $34 \%$ near the cathode. The highest DNT degradation was achieved using LM-

14 NIP. The total degradation of DNT was attributed to both NIP and electrochemical process.

15 Overall it was found that electrokinetic system can enhance the delivery of nanoscale iron

16 particles in low permeability soils for the degradation of energetic organic contaminants such as

17 DNT.

19 KEYWORDS: Electrokinetic remediation, Nanoscale iron particles, Dinitrotoluene, Aluminum

20 lactate, Transport, Soils. 


\section{INTRODUCTION}

3 Contamination of soils and groundwater by nitroaromatic and other energetic organic

4 compounds has received attention of environmental professionals due to their harmful effects to

5 public health and the environment. This group of contaminants include compounds such as

6 dinitrotoulene (DNT), trinitrotoluene (TNT), dinitrobenzene (DNB), Hexahydro-1,3,5-Trinitro-

7 1,3,5-Triazine (RDX) and others. The origin of these pollutants in the environment is mainly

8 associated to the production, storage and use of military munitions. These compounds can

9 contaminate the soils and remained attached to the soil particle surfaces but mainly associated

10 with the organic matter. Despite the low solubility of these compounds, groundwater flux can

11 partially dissolve the contaminants and spread the contamination in the subsurface [1].

12 Moreover, they are transformed or degraded extremely slowly through natural processes.

13 Furthermore, upward advection also contributes to the dispersion in soils induced by

14 evaporation. This process is affected by soil temperature [2]. DNT is a common contaminant

15 associated to munitions production although it is not used as an explosive, but it is used as a

16 precursor of TNT. DNT is considered to be toxic and mutagenic to humans [3], and continuous

17 exposure may result in organs damage. DNT has been listed as a priority pollutant by the United

18 States Environmental Protection Agency (USEPA) due to its acute toxicity and carcinogenicity $19[3-5]$.

21 Remediation technologies for nitroaromatic contaminated sites involve the use of separation

22 processes (resin adsorption, liquid-liquid extraction or ultrafiltration), advanced oxidation

23 processes, chemical reduction, bioremediation and phytoremediation [1]. Several studies have 
1 demonstrated that nanoscale zero-valent iron particles can be used in environmental engineering.

2 Thus, nanoscale iron particles (NIP) can be used in the reductive degradation of nitroaromatic

3 compounds [6,7] and other contaminants often identified in soils and groundwater such as

4 chlorinated organic solvents, organochlorine pesticides, polychlorinated biphenyls (PCBs),

5 organic dyes [8,9]. Furthermore, various inorganic compounds (nitrate and heavy metals) can

6 also be remediated for soil by NIPs [10]. For instance, the chlorinated reduction of

7 pentachlorophenol (PCP) in clayey soil can be achieved with NIP, reaching removal as high as

$890 \%$ within $24 \mathrm{~h}$ treatment [11]. Despite these promising results, the limited transport of NIP

9 through soils has been reported to be a major drawback for in-situ remediation applications.

10 Adams [12] reported that bare NIP could not transport through porous media due to

11 agglomeration of NIP, which increases the particle size, making it difficult to move through the

12 soil pores. Particle aggregation increases the rate of settlement and particles are not well

13 dispersed to be transported into the soil $[13,14]$. Nanoparticle aggregation might be due to the

14 strong van der Waals forces and magnetic attraction among particles.

16 Several studies have been performed to improve the dispersion and transport of NIP in soils.

17 Different modifiers or dispersants were used to coat the particles in order to reduce the strong

18 electrostatic attraction and increase steric repulsion among the particles. Cameselle et al. [15]

19 investigated a range of dispersants such as surfactants, polymers, lactates and cyclodextrines.

20 Based on zeta potential and column experiments, these researchers reported that $10 \%(\mathrm{w} / \mathrm{w})$ of

21 aluminum lactate has the potential of enhancing the transport of NIP through soils. Other studies

22 have used a wide range of different chemicals such as polyacrylic acid, guar gum and starch, to

23 modify the particle surface. Modifiers have the potential to aid the transport of NIP through soils, 
1 but not all of these chemicals are considered environmentally friendly [14,16-18]. Despite the

2 ability of these dispersants to improve the delivery of NIP through highly porous media such as

3 sand, it is still a challenge to transport the NIP through low permeability soils such as fine sands

4 and clays $[19,20]$.

5

6 Electrokinetic transport of NIP may help in the delivery of nanoparticles into low permeability

7 soils. Cardenas and Struble [21] were able to electrokinetically deliver nanoparticles to hardened

8 cement paste using small voltage of about $0.03 \mathrm{~V} / \mathrm{cm}$ for about $5 \mathrm{~min}$. Even during the transport

9 of nanoparticles, permeability was reduced by about 1-3 orders of magnitude due to the reaction

10 between $\mathrm{SiO}_{2}$ and $\mathrm{Al}_{2} \mathrm{O}_{3}$ nanoparticles. Pamukcu et al. [22] tested the transport of modified NIP

11 through clay by electrokinetics. NIP were coated with polyvinyl alcohol-co-vinyl acetate-co-

12 itaconic acid showing positive surface charge. NIP effectively moves from anode to cathode

13 through a clay sample with $60 \%$ moisture content, whereas diffusion was not able to transport

14 nanoparticles. However, corrosion of NIP occurs at low pH and high ORP in the anode, whereas

15 passivity occurs at the cathode end of the clay with high ORP.

17 Yang et al. [17] showed that polyacrylic acid modified NIP can be transported horizontally about

$1825 \mathrm{~m}$ through packed loam soil using electrokinetics, whereas, NIP only travel about $0.25 \mathrm{~m}$ in a

19 vertically packed column without electric field. Chang [23] combined electrokinetics (1

$20 \mathrm{DCV} / \mathrm{cm}$ ) with emulsified nano-zero-valent-iron slurry (ENZVIS) to degrade trichloroethlyne

21 (TCE) in soils. The results showed that the best port of injection of ENZVI was at the cathode

22 due to the corrosion of NIP when injected at the anode. Conversely, Yang [9] reported that the

23 best port for NIP injection is at the anode and studied the degradation of TCE in soils combining 
1 NIP and electrokinetics. NIP surface was modified with 3\% soluble starch and other dispersants.

2 The results indicated that about $99 \%$ of TCE was degraded. Similarly, Yang et al. [24]

3 investigated the degradation of nitrate in soils combining electrokinetics and nanoscale

4 palladium-iron $(\mathrm{Pd} / \mathrm{Fe})$ particles. Again, anode was found to be the best position for nanoparticle

5 injection, compared to the cathode or any other position in between the electrodes. About $99 \%$

6 nitrate was removed when about $0.05 \%$ wt. of $\mathrm{Pd} / \mathrm{Fe}$ was injected. The researchers attributed the

7 nitrate degradation to the movement of nitrate ions towards the anode where the nanoscale $\mathrm{Pd} / \mathrm{Fe}$

8 particles exist.

10 Reddy et al. [20] performed a comprehensive research program at UIC (Chicago, IL, USA) to

11 investigate the delivery and reactivity of bare and modified NIP through low and high

12 permeability soils contaminated by organic pollutants. Hydraulic delivery of bare NIP and

13 lactate-modified NIP (LM-NIP) into high permeability soils such as sands has been demonstrated

14 to remediate PCP and DNT. Reddy and Karri [11,25] investigated the potential electrokinetic

15 delivery of bare NIP in low permeability soils contaminated with chlorinated organic

16 compounds. The study included conducting bench-scale experiments using bare NIP. Iron

17 nanoparticles could not transport into clayey soil due to rapid aggregation and settlement, and

18 moreover, partial premature oxidation of NIP was found to occur at the anode. PCP was partially

19 degraded and mostly in the cathode by reductive dechlorination, and not due to the reductive

20 capacity of NIP. In order to enhance NIP transport into the soil by electrokinetics, the authors

21 decided to modify NIP surface with a nonionic surfactant (5\% Igepal CA720) or a co-solvent

22 (5\% ethanol) and placed it in the anode chamber. The results showed that electroosmotic flow

23 was not affected by the presence of surfactant or co-solvent. Still, the amended NIP showed 
1 limited transport similar to the case without amendment. The reduction of PCP was slightly

2 greater in the co-solvent system than the surfactant system probably due to the enhanced

3 solubilization and transport of PCP into the cathode area.

4

5 The present study investigated the electrokinetic delivery and reactivity of aluminum lactate

6 modified nanoscale iron particles (LM-NIP) into clayey soil contaminated with dinitrotoluene

7 (DNT). Bench-scale electrokinetic experiments were performed to investigate the extent of

8 transport of LM-NIP and resulting improvement in degradation of DNT.

MATERIALS AND METHODS

\section{Nanoscale iron particles (NIP)}

13 NIP used in this study were obtained from Toda Kogyo (Japan). The particles had an average

14 diameter of $70 \mathrm{~nm}$ (with a range of 50-300 nm), the original $\mathrm{pH}$ of NIP suspension was 10.7 and

15 the specific surface calculated by BET isotherm was $37.1 \mathrm{~m}^{2} / \mathrm{g}$. An image of the rugged surface

16 of NIP obtained by scanning electron microscopy is shown in Fig. 1(a). NIP consisted of an

17 elemental iron core $(\alpha-\mathrm{Fe})$ and a magnetite shell $\left(\mathrm{Fe}_{3} \mathrm{O}_{4}\right)$ as shown in Fig. 1(b). The approximate

18 composition of NIP was $50 \%$ wt. $\alpha$-Fe core and $50 \%$ wt. $\mathrm{Fe}_{3} \mathrm{O}_{4}$. The density of the commercial

19 NIP suspension was $1.27 \mathrm{~g} / \mathrm{mL}$ at solid concentration of $25.6 \% \mathrm{wt}$. These particles are

20 manufactured in bulk and available presently (2010) at a cost of $\$ 25$ to $\$ 30$ per pound. Because

21 of their nontoxic characteristics and relatively low cost, these particles are suitable for

22 environmental remediation. It is interesting to note that NIPs posses electromagnetic properties

$23[26,27]$ that may favor their interaction and aggregation. 


\section{Chemicals}

3 2,4-dinitrotoluene (DNT) was selected as a representative munitions waste compound which is

4 included in the list of priory pollutants by the USEPA due to its acute toxicity and carcinogenity.

5 2,4- DNT (97\% purity) with a chemical formula $\mathrm{CH}_{3} \mathrm{C}_{6} \mathrm{H}_{3}\left(\mathrm{NO}_{2}\right)_{2}$ was obtained from Aldrich

6 chemical company, its aqueous solubility is $270 \mathrm{mg} / \mathrm{L}$ and $\log \mathrm{K}_{\mathrm{ow}}$ is 1.98 at $25^{\circ} \mathrm{C}\left(\mathrm{K}_{\mathrm{ow}}\right.$ refers to

7 octanol-water partition coefficient). Aluminum lactate was used for surface modification of NIP.

8 It was chosen out of a host of other dispersants [15] since it is more environmentally friendly and

9 was able to promote the transport of NIP in high permeability soils [20]. Aluminum lactate with

10 CAS number 18917-91-4 and molecular formula $\mathrm{C}_{9} \mathrm{H}_{15} \mathrm{AlO}_{9}$ was obtained from Aldrich.

11 Electrolyte solution was used in all the experiments in order to simulate groundwater conditions.

12 This was done due to the fact that the use of deionized water would not represent pore water

13 composition in real-world soils. The electrolyte solution contained $0.006 \mathrm{M}$ of sodium

14 bicarbonate, $0.002 \mathrm{M}$ of calcium chloride and $0.001 \mathrm{M}$ of magnesium chloride. $\mathrm{pH}$ of electrolyte

15 solution was adjusted with $\mathrm{HCl} / \mathrm{NaOH}$ to 7.5-7.6. Total dissolved solids and electrical

16 conductivity of the electrolyte solution were $500 \mathrm{mg} / \mathrm{L}$ and $1020 \mu \mathrm{S} / \mathrm{cm}$, respectively.

18 Soil

19 Kaolinite clay (kaolin) was used for this study to represent low permeability soil. NIP transport

20 can be achieved in high porosity soils but the real transport problems arise in clayey soils where

21 permeability is low. Kaolin is often used in electrokinetic research because it has been studied

22 extensively, it has a low organic content, consistent and uniform mineralogy, it is fairly non-

23 reactive, and it has a low cation exchange capacity [28]. Thus, kaolin is a good control soil for 
1 laboratory electrokinetic testing because the amount of experimental variation as a result of soil

2 heterogeneity is minimized and the influence of variables such as flushing solutions or voltage

3 gradient in the electrokinetic treatment can be drawn easily. The properties of the kaolin used in

4 this study are shown in Table 2.

6 Electrokinetic reactor

7 Experiments were performed in a bench-scale electrokinetic reactor specially designed for this

8 study. A schematic of the electrokinetic reactor setup is shown in Fig. 2. The reactor simulates

9 one-dimensional NIP and contaminant transport under the influence of electrical gradient. The

10 reactor consisted of a reactor cell to hold the soil sample, two electrode compartments at both

11 ends, and an injection compartment which was located about $3 \mathrm{~cm}$ from the anode compartment.

12 The experimental set-up also includes a power supply, a multimeter, and other peripherals such

13 as C-Flex tubing (Cole Parmer Instrument Company) wiring, and stands. The reactor cell was

14 made of cylindrical Plexiglass ${ }^{\circledR}$ and it had a $3.81 \mathrm{~cm}$ inside diameter and a $13.5 \mathrm{~cm}$ length, so its

15 volume was approximately $150 \mathrm{~cm}^{3}$. Each electrode compartment was also made of Plexiglass ${ }^{\circledR}$

16 and contained Whatman filter paper, a porous stone, and a slotted graphite electrode. The No. 1

17 Whatman filter paper retains particles with diameters greater than $11 \mu \mathrm{m}$ and the porous stone

18 retains particles with diameters greater than $250 \mu \mathrm{m}$, and both the filter paper and the porous

19 stone were used to prevent soil particles from entering into the anode or cathode reservoir. The

20 filter paper was placed between the soil and the porous stone, and both were placed in front of

21 the electrode. Gas vents were provided in the electrode compartments to allow gases resulting

22 from the electrolysis reactions to escape. 


\section{Experimental procedure}

2 For all the electrokinetic experiments, kaolin was spiked with DNT (2,4-Dinitrotoulene) at a

3 target concentration of $1000 \mathrm{mg} \mathrm{DNT} / \mathrm{kg}$. About $600 \mathrm{~mL}$ hexane was used to dissolve $1000 \mathrm{mg}$

4 of solid DNT. To ensure all the DNT solids were dissolved, the DNT-hexane mixture was placed

5 on a magnetic stirrer for about 45 minutes. One $\mathrm{kg}$ kaolin was weighed in a large glass beaker.

6 The hexane-DNT solution was added to the soil in the beaker and mixed well with a stainless

7 steel spoon continuously for about 30 minutes to ensure the DNT was uniformly distributed. The

8 soil-hexane-DNT mixture was placed in a ventilation hood nearly 7 days for the mixture to dry.

9 During the drying period, the soil was mixed regularly to ensure uniform spiking and drying. The

10 final DNT concentration in the spiked kaolin was $920 \mathrm{mg} / \mathrm{kg}$.

12 DNT spiked kaolin was moistened with electrolyte solution to achieve initial moisture content of

$13 \quad 35 \%$ (by dry weight) before it was placed into the electrokinetic cell. The moist kaolin was

14 placed in the electrokinetic cell in layers and compacted manually using a stainless steel rammer.

15 Once the cell was loaded with the spiked soil, the electrode compartments were attached at both

16 ends of the cell tightly to prevent leakage. The reservoirs at both ends (anode and cathode) were

17 filled with electrolyte solution and the system was left for $24 \mathrm{~h}$ to allow the saturation of the

18 kaolin specimen, after which the NIP solution was introduced through the injection point located 19 at $3 \mathrm{~cm}$ from the anode.

21 A series of transport and reactivity experiments were performed and the details of the operating

22 conditions of each experiment are summarized in Table 3. NIP slurry with a concentration of 4

$23 \mathrm{~g} / \mathrm{L}$ was used as the flushing solution. The effect of aluminum lactate in the transport of NIP was 
1 analyzed by adding $10 \%$ aluminum lactate (w/w NIP) to the NIP slurry (LM-NIP). Clean and

2 DNT-spiked soil samples were tested using NIP and LM-NIP to accentuate the effects of DNT

3 on the transport of NIP or LM-NIP. The NIP or LM-NIP solution was injected through a

4 reservoir at a distance of $3 \mathrm{~cm}$ from the anode end. The injection location was chosen to avoid

5 oxidation of NIP under oxygenated and acidic conditions in the anode [25, 29]. Baseline

6 experiment was conducted on DNT-spiked soil using electrolyte alone as the flushing solution

7 (without using NIP or LM-NIP). A voltage gradient of $1 \mathrm{VDC} / \mathrm{cm}$ was applied in all the tests

8 with current and flow monitored periodically throughout the test. The current was automatically

9 recorded using a data acquisition system, but the flow was manually recorded by observing the

10 levels of the liquids in the three reservoirs; anode and cathode reservoirs and injection reservoir.

11 The reservoir levels were controlled manually to avoid any influence of hydraulic gradient on the

12 electroosmotic flow. At the end of each experiment the soil was extruded from the cell and

13 sectioned into three parts. $\mathrm{pH}$, oxidation reduction potential (ORP), total dissolved solids (TDS),

14 conductivity, and iron and DNT concentrations were determined in liquid samples from the

15 anode and cathode reservoirs, and in soil sections.

\section{Analyses}

18 The concentration of 2,4-DNT in soil extracts was determined using gas chromatography (GC)

19 according to EPA Method 8091 [30]. The soil samples were extracted for $24 \mathrm{~h}$ with a

20 mixture of acetone-acetonitrile (1:1, v/v) using a soil:solvent extraction ratio of 1:50 (g:mL),

21 where the extraction efficiency was greater than $95 \%$. The soil extracts were centrifuged at 6,500

$22 \mathrm{~g}$ for $15 \mathrm{~min}$. The liquid extracts were diluted in ethanol. DI water was added to the diluted

23 ethanol samples, and sodium hydroxide was added to the water-ethanol dilutions. Liquid-liquid 
1 extraction was performed to transfer the 2,4-DNT from the diluted aqueous water-ethanol phase

2 into an hexane phase for GC analysis. For GC analysis, 1-chloro-3-nitrobenzene was used as

3 surrogate standard. The hexane extracts were injected into an Agilent 6890 Series GC

4 (Wilmington, DE) with a microelectron capture detector (ECD) for analysis of 2,4-DNT. A DB-5

5 (J\&W, Folsom, CA) capillary GC column was used with helium and argon-methane as column

6 carrier and detector makeup gases, respectively [31]. Iron was measured using acid digestion and

7 atomic absorption spectrometry [30].

9 RESULTS AND DISCUSSION

10 The results of the electrokinetic experiments were analyzed to determine the effect of applied

11 electric potential on electric current, electro-osmostic flow, ORP, conductivity, $\mathrm{pH}$, transport of

12 NIP and LM-NIP and removal and degradation of DNT in kaolin. Testing with bare NIP and

13 LM-NIP allowed investigation of the benefits of lactate modification of NIP, and testing with

14 clean kaolin (kaolin not spiked with DNT) helped to investigate the transport of NIP without any

15 influence of reactions between NIP and DNT.

\section{Electric current}

19 Fig. 3 shows the profile of electric current intensity with treatment time. Current intensity

20 follows similar trend for all the tests. At the very beginning, current intensity increased rapidly

21 and peaked at 9-12 mA. Then, the current decreased, dropping to a value below $4 \mathrm{~mA}$ within the

22 first $24 \mathrm{~h}$. Finally, the electric current stabilized at a low value that ranges from 0.1 to $1 \mathrm{~mA}$ with

23 increased treatment time. The maximum current recorded in the tests with LM-NIP for both 
1 contaminated and clean soil were, respectively, about $9.5 \mathrm{~mA}$ and $12 \mathrm{~mA}$. Similarly, the

2 maximum current intensity in the test with contaminated soil and NIP was higher than that with

3 clean soil. These results indicate that the presence of DNT might have caused decrease in the

4 current intensity due to its hydrophobic nature that may act as a dielectric between the soil

5 particles and the interstitial fluid. It is also worth noting that the presence of aluminum lactate

6 aided in increasing the current intensity slightly as compared with the tests with bare NIP. The

7 presence of small amounts of $\mathrm{Al}^{3+}$ and lactate ions increase the ionic concentration in the

8 interstitial fluid and therefore its conductivity, resulting in a small but significant increase of

9 current intensity, and charge transport between the anode and cathode.

11 The evolution of the current intensity in the electrokinetic treatment of a spiked kaolin specimen

12 shows a rapid increase from very low values. The increase of current intensity is attributed to

13 significant $\mathrm{H}^{+}$and $\mathrm{OH}^{-}$ions are generated at the anode and cathode due to electrolysis of water.

14 The increase of ion concentration in the chambers results in the decreasing of the electric

15 resistance and therefore, in the increasing of the electric current. Furthermore, the increased

16 mobility of ions in the soil as a result of dissolution of precipitated salts and desorption of

17 adsorbed ions [11] also contributes to the electric current. Current intensity will be the sum of the

18 charge transport by the ions into the soil and the $\mathrm{H}^{+}$ions electrogenerated at the anode. The ions

19 move due to the process of electromigration and electro-osmosis, and the concentration of ions

20 turn to reduce into the soil resulting in the dropping of the current intensity. Furthermore, the

$21 \mathrm{OH}^{-}$ions electrogenerated at the cathode will increase the soil $\mathrm{pH}$ close to the cathode end. High

$22 \mathrm{pH}$ decreases the solubility of metal ions, forming precipitates that reduce the total amount of

23 ions available to transport charge. It results in a decreasing electric current intensity. Khodadoust 
1 et al. [31] report a decreasing profile of electric current intensity in kaolin spiked with DNT,

2 however, the electrokinetic tests conducted with DNT spiked glacial till shows fluctuations. This

3 was attributed to the more diverse mineral composition of glacial till (compared with kaolin) and

4 possible non-uniform mineral dissolution. The comparison of the experimental results of this

5 study with those from the literature states that the electric current intensity is more affected by

6 the geochemical nature of the soil matrix and the electrolysis of water at the electrodes. The

7 presence of DNT contaminant and the aluminum lactate in low concentrations seem to play only

8 a secondary role in the final observable current intensity.

\section{Electro-osmotic flow}

11 Cumulative electro-osmotic flow measured at the cathode in the tests with clean and DNT-

12 contaminated kaolin with NIP or LM-NIP is shown in Fig. 4. The results of baseline test

13 involving DNT-contaminated kaolin without the use of either NIP or LM-NIP are also shown for

14 comparison. The electro-osmotic flow in all experiments continuously increased with time;

15 however, the flow rate was much higher in the beginning and then decreased and remained

16 almost constant during most of the treatment time. The initial high flow is a result of initial high

17 currents in all the tests, and then flow drops as current drops. Thus, the tests with contaminated

18 soil with aluminum lactate showed higher cumulative flow (121 $\mathrm{mL}$ in the LM-NIP test) than

19 that with bare NIP $(95 \mathrm{~mL})$, and this phenomenon occurred also with tests with clean soil: 180

$20 \mathrm{~mL}$ in LM-NIP compared to $98 \mathrm{~mL}$ with bare NIP. The reason may be due to the increase in

21 current as a result of increased ion concentration into the soil that results in a higher flow rate.

$23 \mathbf{p H}$, ORP, conductivity and TDS 
2 The profile of the $\mathrm{pH}$ of the soil specimen after the tests is shown in Fig. 5. In all the tests, the $3 \mathrm{pH}$ increases from the anode to the cathode side. The electrolysis of water produces $\mathrm{H}^{+}$ions at

4 the anode and decreases the $\mathrm{pH}$ in the section of soil close to the anode to a range between 2.5

5 and 3.5. On the cathode side, the $\mathrm{pH}$ is very alkaline, about 11.5 , in the baseline test; but the

6 presence of NIP, aluminum lactate and the contaminant DNT affected the electroosmotic flow.

7 The increase of the electrosmotic flow towards the cathode favored the transport of ions and the

8 advance of the acid front from the anode. Thus, lower $\mathrm{pH}$ values were found on the cathode side

9 in the other tests. The $\mathrm{pH}$ in the central section of the soil has an intermediate value between the

10 anode and the cathode. The $\mathrm{pH}$ of the liquids (Fig. 6a) in the anode and cathode compartment

11 shows a similar behavior: an acid $\mathrm{pH}$ on the anolyte and a very alkaline $\mathrm{pH}$ on the catholyte due

12 to the electrolysis of water. The $\mathrm{pH}$ in the NIP injection point is an intermediate value between

13 the anolyte and the catholyte. The initial $\mathrm{pH}$ of the NIP suspension introduced in the injection

14 location is about 10 , but this is rapidly decreased as a result of the migration of $\mathrm{H}^{+}$ions from the 15 anode.

17 The oxidation-reduction potential (ORP) of the liquid in the electrode compartments and 18 injection compartment was measured at the end of the test (Fig. 6b). The solution at the anode 19 was found to be more oxidized than at the cathode and the injection compartment. The ORP at 20 the anode reservoir was about $400 \mathrm{mV}$ whereas that of the injection point and the cathode 21 compartment was $180 \mathrm{mV}$ and $-20 \mathrm{mV}$ respectively. These results are due to the effect of the 22 electric field that creates oxidizing environment at the anode and a reduction medium at the 23 cathode. The profile of the ORP follows the same pattern as $\mathrm{pH}$, which may indicate that lower 
$1 \mathrm{pH}$ results in an increase in ORP. Conductivity and total dissolved solids (TDS) of the liquids at

2 the end of the tests are shown in Fig. 6c and 6d, respectively. The results show that conductivity

3 and TDS are higher in the effluent at the cathode compartment than at the anode compartment,

4 probably due to the ionic electromigration and electroosmosis towards the cathode, that increases

5 the ionic species in that compartment.

\section{Transport of NIP and LM-NIP}

9 After the completion of each experiment, the soil sample was extruded from the reactor cell and

10 sectioned into three parts. The total iron concentration was determined in each section in order to

11 investigate the extent of the transport of NIP in the soil with an electric field as a driving force.

12 Fig. 7 shows the concentration of NIP in the various sections after the completion of the

13 experiments. The baseline test conducted without NIP showed that the concentration of native

14 iron in the soil ranges from 1600 to $1680 \mathrm{mg} / \mathrm{kg}$ dry wt. The other tests conducted with NIP or

15 LM-NIP show higher concentration of iron than the baseline test for all the sections. It confirms

16 that there is an effective NIP transport through the soil towards the cathode by electrokinetics.

18 The highest iron concentrations were determined near the NIP injection location (it corresponds

19 with section 1 in Fig. 7). Iron concentrations decreases with the distance towards the cathode.

20 The test with contaminated soil and NIP showed $2184 \mathrm{mg} / \mathrm{Kg}$ iron concentration in section 1,

21 which reduced to about $1760 \mathrm{mg} / \mathrm{Kg}$ at section 3 . In the test with clean soil and NIP, iron

22 concentration ranges from about 2100 to $1806 \mathrm{mg} / \mathrm{Kg}$. The iron concentration in the first section

23 of the LM-NIP tests for uncontaminated soil was about $2002 \mathrm{mg} / \mathrm{Kg}$ near the injection 
1 compartment which gradually reduces to about $1835 \mathrm{mg} / \mathrm{Kg}$ at the third section (near the

2 cathode). Finally, the concentration of iron for LM-NIP test with contaminated soil ranges from

32071 and $1807 \mathrm{mg} / \mathrm{Kg}$. These results show that the increase in iron concentration in sections 2

4 and 3 for the LM-NIP tests was much important than that of NIP tests. Conversely, the

5 concentration of iron in section 1 for LM-NIP test is lower than that of NIP tests due to the major

6 migration of NIPs towards the cathode. Comparing the concentrations of iron in sections 2 and 3 ,

7 it can be observed that the NIP transport through the soil was enhanced between 5-25\% for clean

8 soil, and about $60 \%$ for DNT contaminated soil. It means that the transport of bare NIP is limited

9 due to the electrostatic interaction among nanoparticles, whereas aluminum lactate modification

10 clearly enhances the transport of NIP through the soil towards the cathode.

12 The differences in the extent of NIP transport may be attributed to aggregation of the particles at

13 the injection compartment and the quick settlement of particles due to the strong van der Waals

14 forces and magnetic attractions. Thus, when the particles aggregate they become larger than the

15 soil pores, making it difficult to transport them through the soil. However, the use of aluminum

16 lactate might have reduced the strong steric attractions, thereby helping to increase the transport

17 of NIP from the injection point to the cathode. The presence of lactate forms a light layer around

18 the particles which makes them more dispersed and helps to protect the particles from

19 oxidization.

\section{Degradation and Removal of DNT}


1 The initial concentration of DNT in the soil (spiked kaolin) used for all the test was $920 \mathrm{mg} / \mathrm{Kg}$.

2 After each test, the soil was sectioned into three parts and the residual concentration of DNT was

3 measured. DNT concentration was also determined in the cathode effluent to find out how much

4 of the DNT was removed from the soil without degradation. It was observed that only about less

5 than $0.5 \mathrm{mg} / \mathrm{L}$ DNT was found in the effluent, despite DNT being slightly soluble in water. In an

6 electrokinetic system electromigration can transport ionizable molecules, so DNT can only be

7 removed by electro-osmosis. However the electro-osmotic flow is not going to be very effective

8 since no solubilizing agents were used in this test [31]. DNT remains attached to the surface of

9 the soil particles and due to its low solubility, its concentration in the interstitial fluid is very low,

10 limiting the possible removal by electro-osmosis. Since the amount of DNT flushed out of the

11 system is negligible, DNT was degraded in the soil or at the cathode, or remained in the soil after

12 the electrokinetic treatment.

14 Fig. 8 shows the DNT remained in the soil in the baseline, NIP and LM-NIP tests. In the baseline

15 test, there was very minimal degradation at both the anode and the cathode side sections. This

16 experiment was conducted with no NIP, and electrolyte was used as flushing solution to simulate

17 a typical groundwater composition. The slight removal at both ends was associated with DNT

18 diffusion into the electrode compartments and subsequent electrochemical degradation. Reddy

19 and Karri $[11,25]$ found similar results whereby pentachlorophenol was degraded by

20 electrochemical reduction at the electrodes.

22 The tests conducted with $4 \mathrm{~g} / \mathrm{L}$ NIP or LM-NIP as flushing solution resulted in much higher

23 DNT degradation. As seen in Fig. 8, the degradation of DNT in the various soil sections varied 
1 along the soil length. Removal of the contaminant was greater in section 1 (near the NIP

2 injection port) than in the section close to the cathode compartment in both experiments. The

3 destruction of DNT at the section close to the injection port is attributed to the heavy presence of

4 NIP. However, the degradation at the section close to the cathode can be a combination of both

5 electrochemical reduction and reductive reduction by NIP. The destruction of DNT was greater

6 when LM-NIP was used. The destruction of DNT with LM-NIP ranged from $65 \%$ to $34 \%$ from

7 the anode to the cathode. However, about $41 \%$ to $30 \%$ of DNT was degraded with bare NIP. The

8 enhanced degradation of DNT with LM-NIP in the three sections of the soil column can be

9 attributed to the fact that lactate helped in the delivery and dispersion of the particles in the soil.

10 In the case of bare NIP, less degradation might have been due to aggregation which has limited

11 transport in the soil. Therefore, effective degradation of DNT was dependent on the contact of

12 the NIP particles with DNT. More degradation with LM-NIP shows that more NIP particles

13 transported into the soil and were able to make contact with the DNT.

15 CONCLUSIONS

16 Dinitrotoluene spiked kaolin was used as model low permeability soil to test the ability of

17 electrokinetics to effectively transport nanoscale iron particles (NIP) into the soil for DNT

18 degradation. Aluminum lactate modified NIP (LM-NIP) were investigated to enhance transport

19 of NIP into the soil and improve DNT degradation. The application of voltage gradient was able

20 to produce electro-osmotic flow in the low permeability kaolin soil when bare NIP or LM-NIP

21 were used. Despite some aggregation of bare NIP, electroosmotic flow was not impeded. Both

22 electroosmotic flow and electromigration influenced the extent of transport of bare and LM-NIP

23 in the soil. Better delivery of NIP into the soil was achieved when using LM-NIP. Highest DNT 
1 degradation was achieved in the test with LM-NIP as compared to bare NIP or baseline tests.

2 The DNT degradation was primarily due to the NIP reductive capacity within the soil and 3 electrochemical reduction of any DNT migrated into the cathode. Electrokinetic system has the

4 potential to enhance the delivery of LM-NIP and degradation of DNT in low permeability soils. 5

\section{ACKNOWLEDGEMENT}

7 Financial support for this project was provided by the U.S. National Science Foundation (Grant

8 CMMI \#0727569), which is gratefully acknowledged. The authors are thankful to Amid

9 Khodadoust and Srinivas Varadharan for their assistance in chemical analysis. 


\section{REFERENCES}

2 [1] J.D. Rodgers, N.J. Bunce, Treatment methods for the remediation of nitroaromatic explosives, Water Res. 35 (2001) 2101-2111.

4 [2] J.M. Phelan, J.L. Barnett, Solubility of 2,4-Dinitrotoluene and 2,4,6-Trinitrotoluene in Water, $5 \quad$ J. Chem. Eng. Data 46 (2001) 375-376.

6 [3] US Environmental Protection Agency (USEPA), National Environmental Policy Act of 1969 (NEPA). USC. 42 (2005) 4321-4347.

[4] D.E. Rickert, B.E. Butterworth, J.A. Popp, Dinitrotoluene: Acute toxicity, oncogenicity,

西

[5] L.H. Keither, W.A. Telliard, Priority pollutants: I-a perspective view, Environ. Sci. Technol. genotoxicity, and metabolism. CRC Crit. Rev. Toxicol. 13 (1984) 217-234.

12 [6] A. Agrawal, P.G. Tratnyek, Reduction of Nitro Aromatic Compounds by Zero-Valent Iron, 13 Metal. Environ. Sci. Technol. 30 (1995) 153-160.

14 [7] Y.S. Keum, Q.X. Li, Reduction of nitroaromatic pesticides with zero-valent iron, $15 \quad$ Chemosphere 54 (2004) 255-263.

16 [8] W.X. Zhang, D.W. Elliott, Applications of iron nanoparticles for groundwater remediation. Remed. J. 16 (2006) 7-21.

18 [9] G.C.C. Yang, Electrokinetic-Chemical Oxidation/Reduction, In Electrochemical

21 [10] M.J. Alowitz, M.M. Scherer, Kinetics of nitrate, nitrite, and $\mathrm{Cr}(\mathrm{VI})$ reduction by iron metal, Environ. Sci. Technol. 36 (2002) 299-306. 
1 [11] K.R. Reddy, M.R. Karri, Removal and Degradation of Pentachlorophenol in Clayey Soil

2 Using Nanoscale Iron Particles, Geotechnics of Waste Management and Remediation, 3 ASCE Press, Reston, Virginia, Geotechnical Special Publication 177 (2008) 463-469.

4 [12] A. Adams, Transport of nanoscale zero valent iron using electrokinetic phenomena. $\mathrm{PhD}$ 5 dissertation, University of Western Australia, Australia (2006).

6 [13] P.G. Tratnyek, R.L. Johnson, Nanotechnology for Environmental cleanup, Nanotoday 1 $7 \quad$ (2006) $44-48$.

8 [14] N. Saleh, K. Sirk, Y. Liu, T. Phenrat, B. Dufour, K. Matyjaszewski, R.D. Tilton, G.V. 9 Lowry, Surface Modifications Enhance Nanoiron Transport and NAPL Targeting in 10 Saturated Porous Media, Environ. Eng. Sci. 24(2007) 45-57.

11 [15] C. Cameselle, K. Darko-Kagya, A. Khodadoust, K. R. Reddy, Influence of Type and 12 Concentration of Dispersants on the Zeta Potential of Reactive Nanoiron Particles, 13 Proceedings of the International Environmental Nanotechnology Conference, USEPA, $14 \quad$ Chicago (2008).

15 [16] B. Schrick, B.W. Hydutsky, J.L. Blough, T. E. Mallouk, Delivery Vehicles for Zerovalent 16 Metal Nanoparticles in Soil and Groundwater, Chem. Mater 16 (2004) 2187-2193.

17 [17] G.C.C. Yang, H.C. Tu, C.H. Hung, Stability of nanoiron slurries and their transport in the 18 subsurface environment, Sep. Purif. Technol. 58 (2007) 166-172.

19 [18] A. Tiraferri, K.L. Chen, R. Sethi, M. Elimelech, Reduced aggregation and sedimentation of 20 zero-valent iron nanoparticles in the presence of guar gum, J. Colloid. Interf. Sci. 324 $21 \quad$ (2008) 71-79. 
1 [19] K.R. Reddy, Transport of Modified Reactive Nanoscale Iron Particles in Subsurface Soils, Proceedings of the Nanotechnology for Site Remediation Workshop, USEPA, Region 5 Superfund Division. (2006).

[20] K.R. Reddy, A.P. Khodadoust, K. Darko-Kagya, Transport and Reactivity of LactateModified Nanoscale Iron Particles in PCP-Contaminated Field Sand, Proceedings of the International Environmental Nanotechnology Conference, USEPA, Chicago. (2008).

[21] H.E. Cardenas, L.J. Struble, Electrokinetic nanoparticle treatment of hardened cement paste for reduction of permeability, J. Mater.Civil Eng. 18 (2006) 546-560.

[22] S. Pamukcu, L. Hannum, J.K. Wittle, Delivery and activation of nano-iron by DC electric field, J. Environ. Sci. Health A 43 (2008) 934-944.

[23] Y.I. Chang, Treatment of Trichloroethlyne in Aqueous Solution Using Nanoscale ZeroValent Iron Emulsion, MS Thesis, National sun Yat-Sen University, Kaohsiung, Taiwan (in Chinese) (2007).

[24] G.C.C. Yang, C.H. Hung, H.C. Tu, Electrokinetically enhanced removal and degradation of nitrate in the subsurface using nanosized Pd/Fe slurry, J. Environ. Sci. Health A 43 (2008) 945-951.

[25] K.R. Reddy, M.R. Karri, Electrokinetic Delivery of Nanoscale Iron Particles for In-situ Remediation of Pentachlorophenol-Contaminated Soils, Proceedings of the International Symposium on Geo-Environmental Engineering for Sustainable Development, Xuzhou, China. (2007).

[26] K. Okinaka, A.D. Jazdanian, A. M. Dahmani, J. Nakano, T. Okita, K. Kakuya, Degradation of trichloroethene with reactive nanoscale iron particles in simulated ground water. 
Preprints of Extended Abstracts presented at the ACS National Meeting, American Chemical Society, Division of Environmental Chemistry. 45 (2005) 662-666.

[27] Y. Liu, H. Choi, D. Dionysiou, G.V. Lowry, Trichloroethene hydrodechlorination in water by highly disordered monometallic nanoiron, Chem. Mater. 17 (2005) 5315-5322.

[28] G. R. Eykholt, Driving and complicating features of the electrokinetic treatment of contaminated soils, Ph.D. dissertation, Univ. of Texas at Austin, Austin, TX. (1992).

[29] K.R. Reddy, M.R. Karri, Electrokinetic Delivery of Nanoiron Amended with Surfactant and Cosolvent in Contaminated Soil, Proceedings of the International Conference on Waste Engineering and Management, Hong Kong. (2008b).

[30] US Environmental Protection Agency (USEPA), Test Methods for Evaluating Solid Wastes, EPA Method SW 846, $3^{\text {rd }}$ Ed., U.S. Government Printing Office: Washington, DC. (1996).

[31] A.P. Khodadoust, K.R. Reddy, O. Narla, Cyclodextrin enhanced electrokinetic remediation of soils contaminated with 2,4-dinitrotoluene, ASCE J. Environ. Engr. 132 (2006). 10431050. 
Table 1. Properties of nanoscale iron particles (NIP).

\begin{tabular}{ll}
\hline Coercive Force $(\mathrm{Hc})$ & $408 \mathrm{Oe}$ \\
\hline Mass Magnetization $(\sigma \mathrm{s})$ & $149.6 \mathrm{emu} / \mathrm{g}$ \\
\hline$\sigma \rho / \sigma \mathrm{s}$ (ratio of ferromagnetism and antiferromagnetism) & 0.152 \\
\hline $\mathrm{pH}$ & 10.7 \\
\hline Surface Area (BET) & $37.1 \mathrm{~m}^{2} / \mathrm{g}$ \\
\hline Electrical Conductivity & $2.2910^{2} \mu \mathrm{S} / \mathrm{cm}$ \\
\hline Particle Size & $50-300 \mathrm{~nm}$ \\
\hline Aqueous Suspension & $20-30 \% \mathrm{wt}$. \\
\hline Density of Aqueous Slurry & $1.2-1.3 \mathrm{~g} / \mathrm{mL}$ \\
\hline
\end{tabular}


Table 2. Properties of kaolinite clay

\begin{tabular}{llc}
\hline & Kaolinite: & $100 \%$ \\
Mineralogy & Illite: & trace \\
& Muscovite: & trace \\
\hline $\begin{array}{l}\text { Particle Size Distribution } \\
\text { (ASTM D 422) }\end{array}$ & 0 & \\
Gravel (\%) & 4 & \\
Sand (\%) & 18 & \\
Silt (\%) & 78 & \\
Clay (\%) & $1.0 \times 10^{-8}$ & \\
\hline Hydraulic Conductivity (cm/s) & 4.9 \\
\hline pH (ASTM 4972) & $\sim 0$ \\
\hline Organic Content (\%)(ASTM D 2974) & CL \\
\hline USCS Classification (ASTM D 2487) & \\
\hline
\end{tabular}


Table 3. Operating conditions of tests.

\begin{tabular}{|c|c|c|c|c|}
\hline Test & Soil Type & Contaminant & Flushing solution & $\begin{array}{c}\text { Electric } \\
\text { Potential } \\
(\mathrm{VDC} / \mathrm{cm})\end{array}$ \\
\hline NIP $^{\mathrm{a}}-$ Clean Soil ${ }^{\mathrm{d}}$ & Kaolin & None & $\mathrm{NIP}^{\mathrm{a}}$ & 1 \\
\hline LM-NIP $^{\mathrm{b}}-$ Clean Soil ${ }^{\mathrm{d}}$ & Kaolin & None & LM-NIP $^{\mathrm{b}}$ & 1 \\
\hline NIP $^{\mathrm{a}}-\mathrm{DNT}^{\mathrm{c}}$ & Kaolin & $\mathrm{DNT}^{\mathrm{c}}$ & $\mathrm{NIP}^{\mathrm{a}}$ & 1 \\
\hline $\mathrm{LM}^{-N I P}{ }^{\mathrm{b}}-\mathrm{DNT}^{\mathrm{c}}$ & Kaolin & $\mathrm{DNT}^{\mathrm{c}}$ & LM-NIP $^{\mathrm{b}}$ & 1 \\
\hline Baseline $^{\mathrm{e}}$ & Kaolin & $\mathrm{DNT}^{\mathrm{c}}$ & Electrolyte & 1 \\
\hline
\end{tabular}

${ }^{\mathrm{a}} \mathrm{NIP}$ : Nanoscale iron particles

${ }^{\mathrm{b}}$ LM-NIP: lactate modified nanoscale iron particles

${ }^{c}$ DNT: dinitrotoluene

${ }^{\mathrm{d}}$ Clean Soil: kaolin specimen without DNT 


\section{Figure Captions}

3 Fig. 1. Nanoscale iron particles (NIP) used in this study: (a) Scanning electron microscopy image

4 and (b) schematic structure.

5 Fig. 2. Electrokinetic test set-up.

6 Fig. 3. Electric current intensity in electrokinetic tests with NIP and LM-NIP.

7 Fig. 4. Electroosmotic flow in clean and DNT contaminated soil with NIP or LM-NIP.

8 Fig. 5. Soil $\mathrm{pH}$ after the electrokinetic treatment in the soil specimen.

9 Fig. 6. a) $\mathrm{pH}$, b) oxidation-reduction potential (ORP), c) conductivity and d) total dissolved solids (TDS), in the electrode (anode and cathode) and NIP (injection point) compartments.

12 Fig. 7. Iron concentration in the soil specimen after the electrokinetic testing with clean and DNT contaminated soil, with NIP or LM-NIP.

14 Fig. 8. Residual DNT in the soil after the electrokinetic testing with NIP and LM-NIP. 
$\begin{array}{ll}1 & \text { Figure } 1 \\ 2 & \end{array}$

3

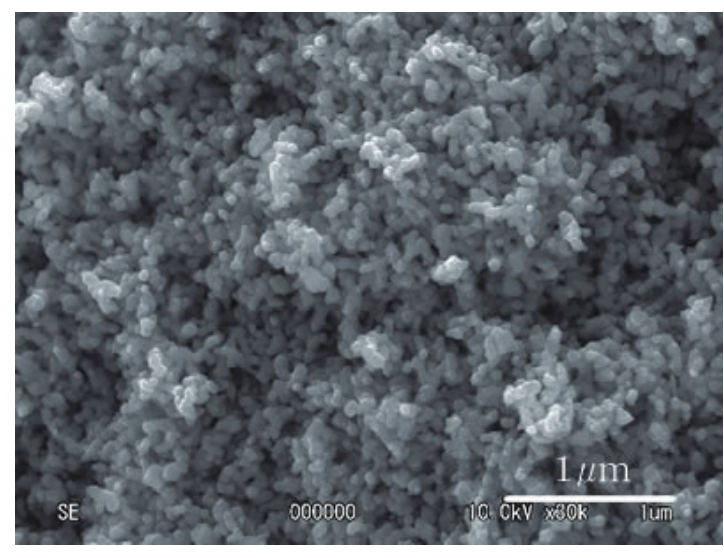

(a)

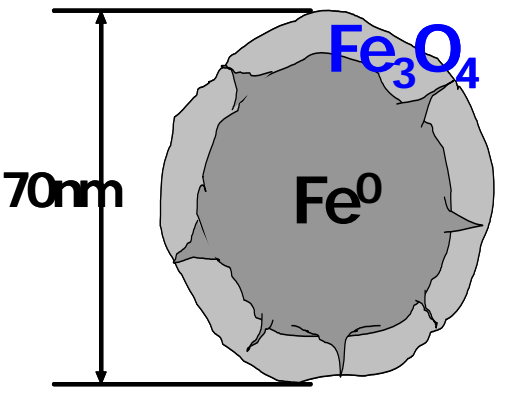

(b) 
1 Figure 2

2

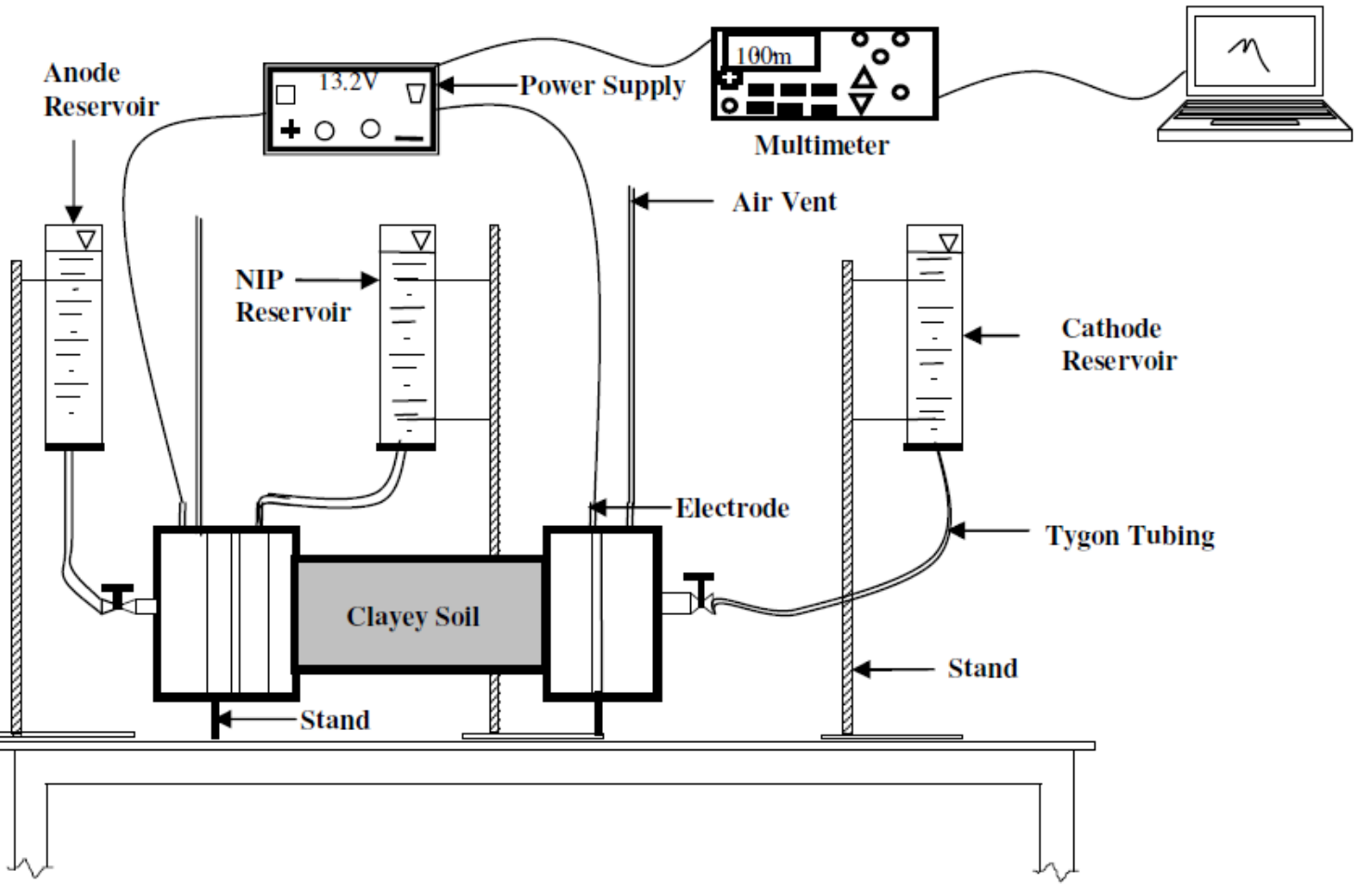


1

2 Figure 3

3

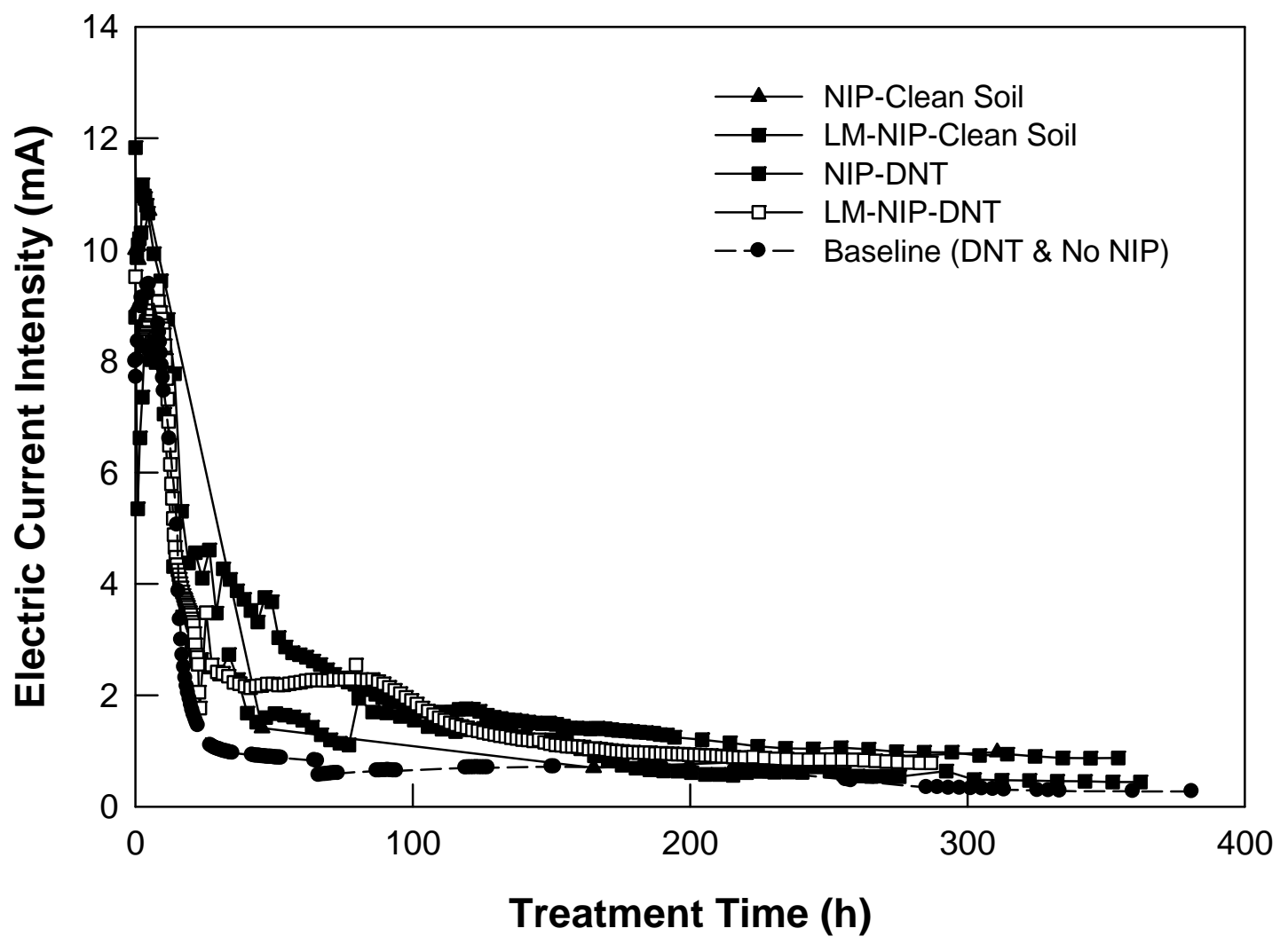

4
5 
1

2 Figure 4

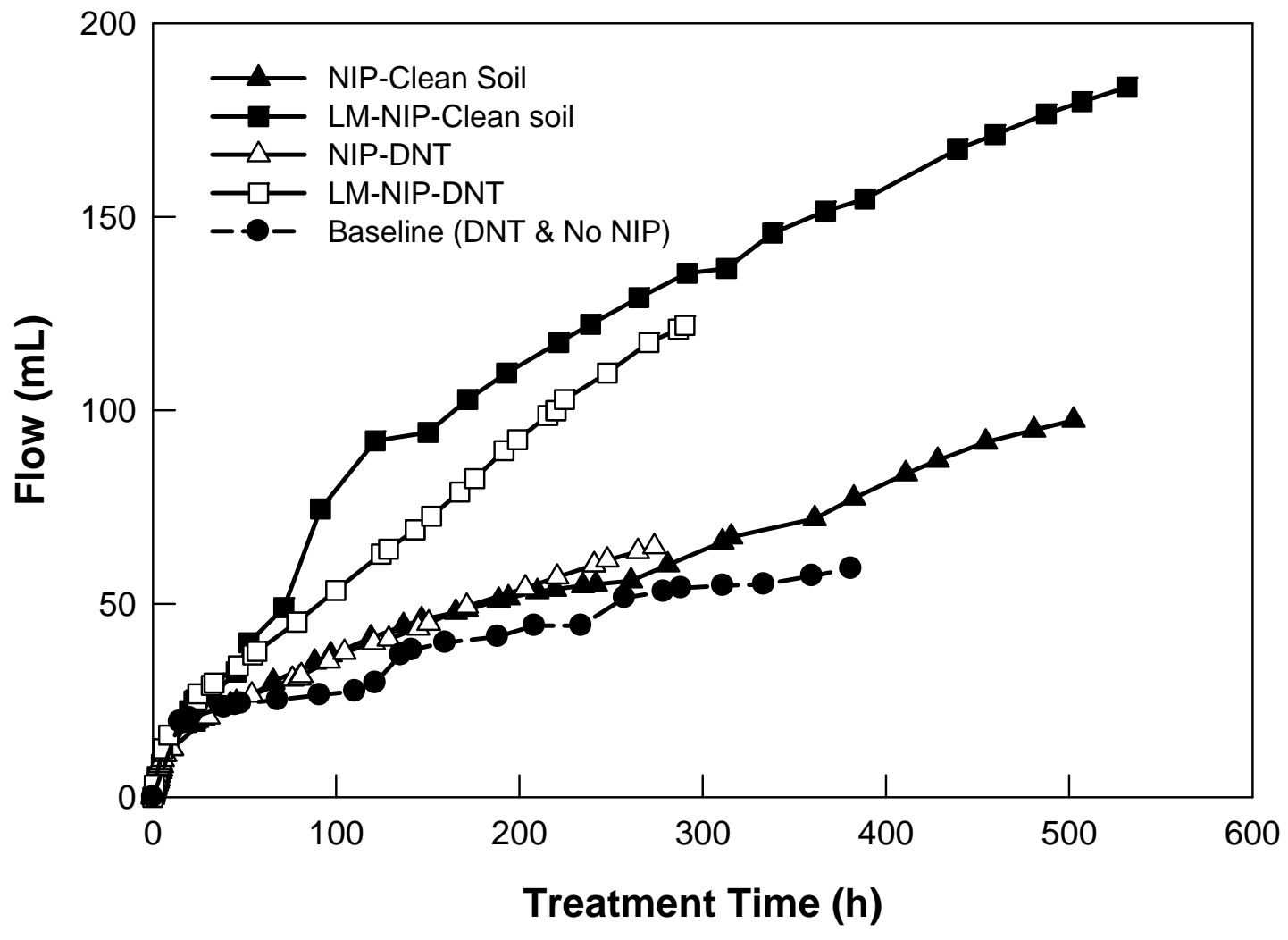

4 
1

2 Figure 5

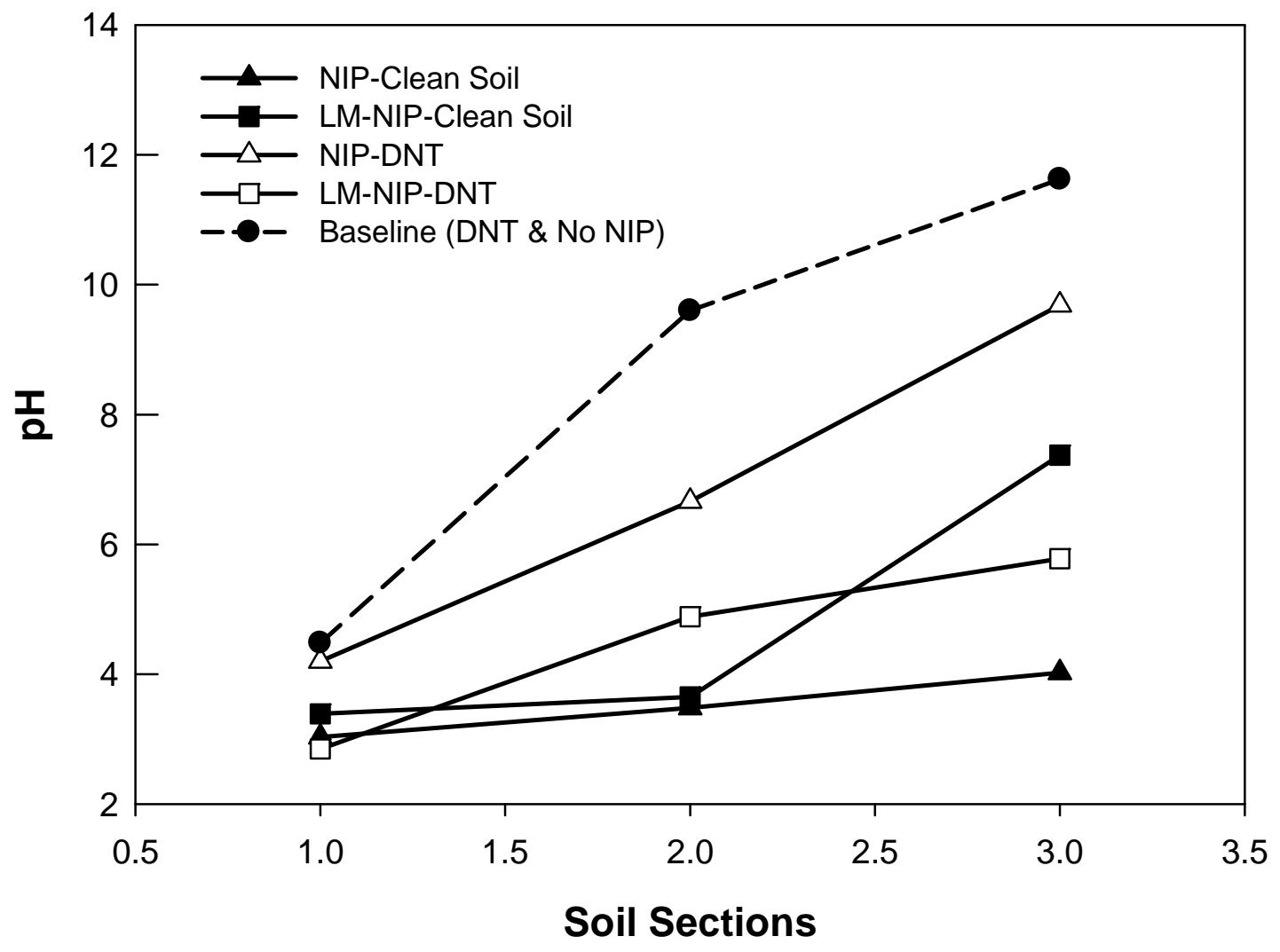


1

2

3

Figure 6

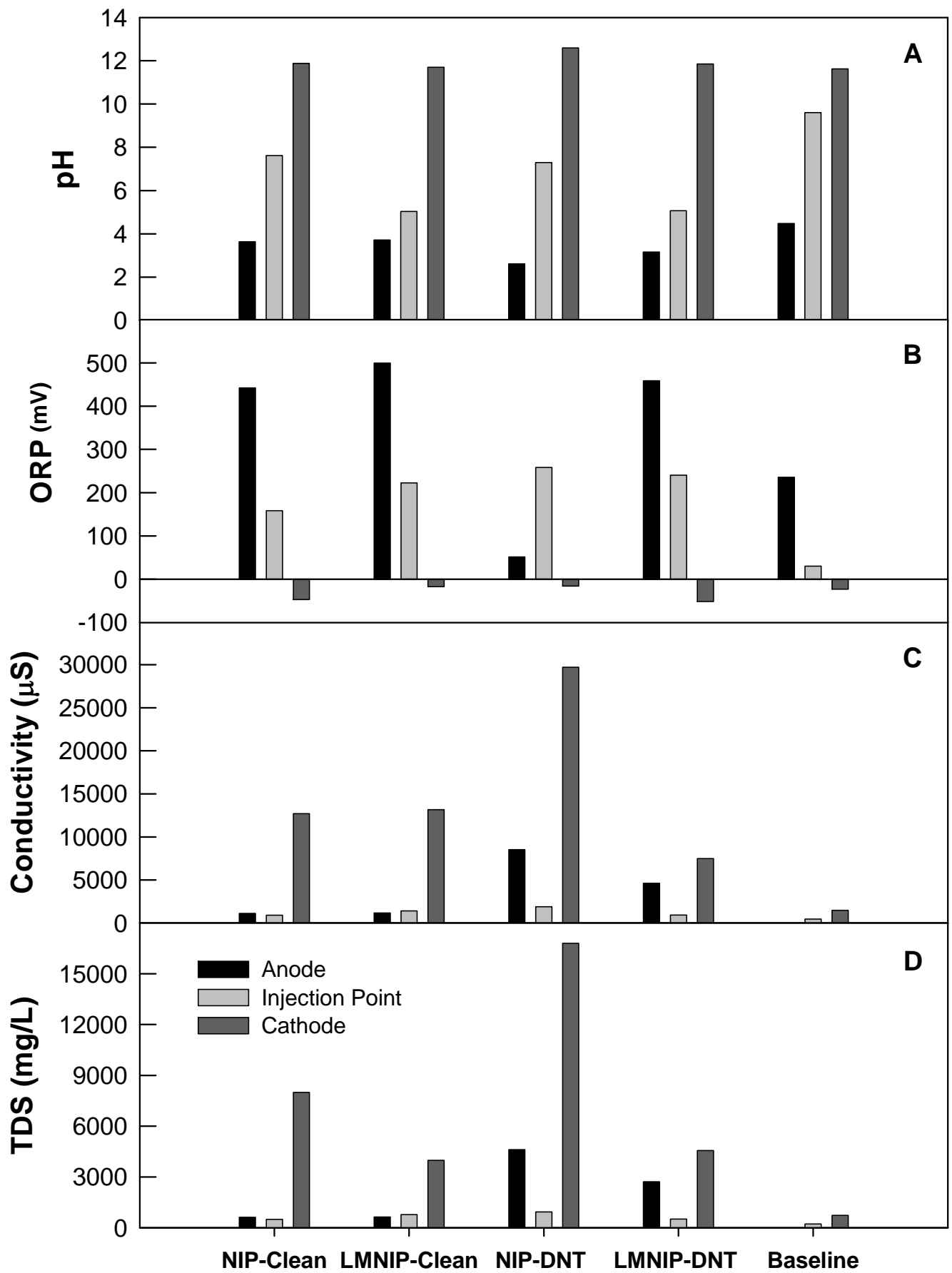




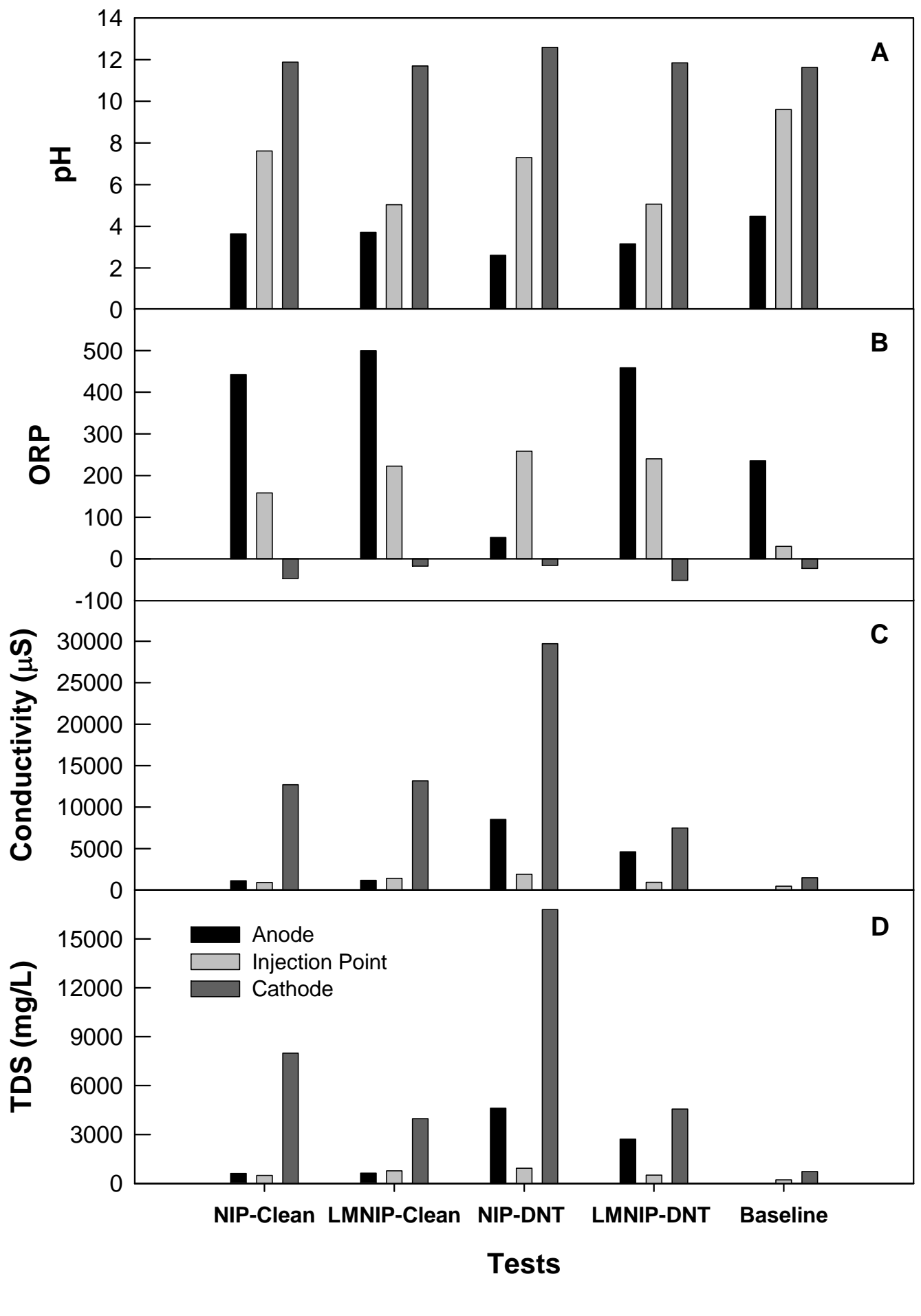


$1 \quad$ Figure 7

2

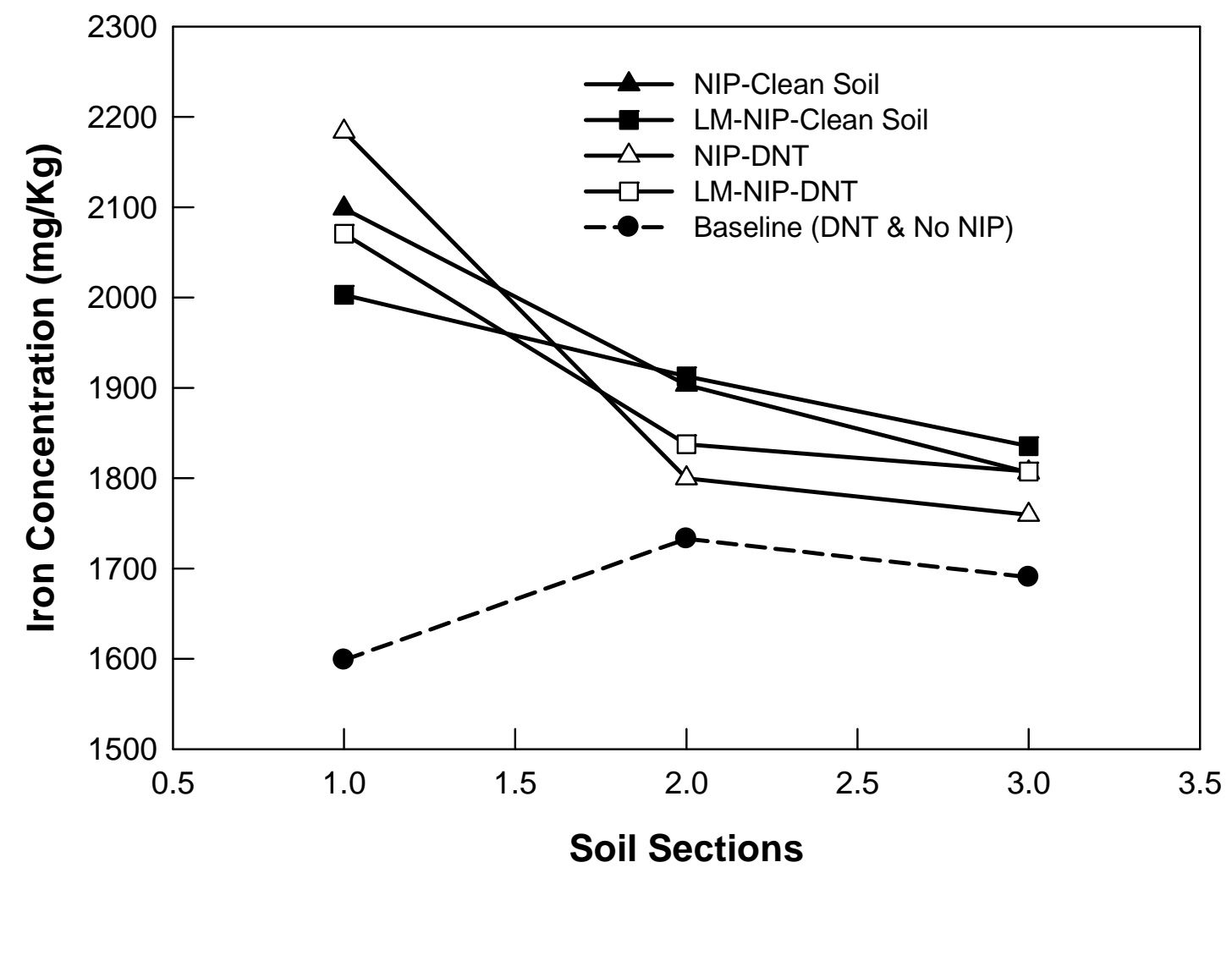


2 Figure 8

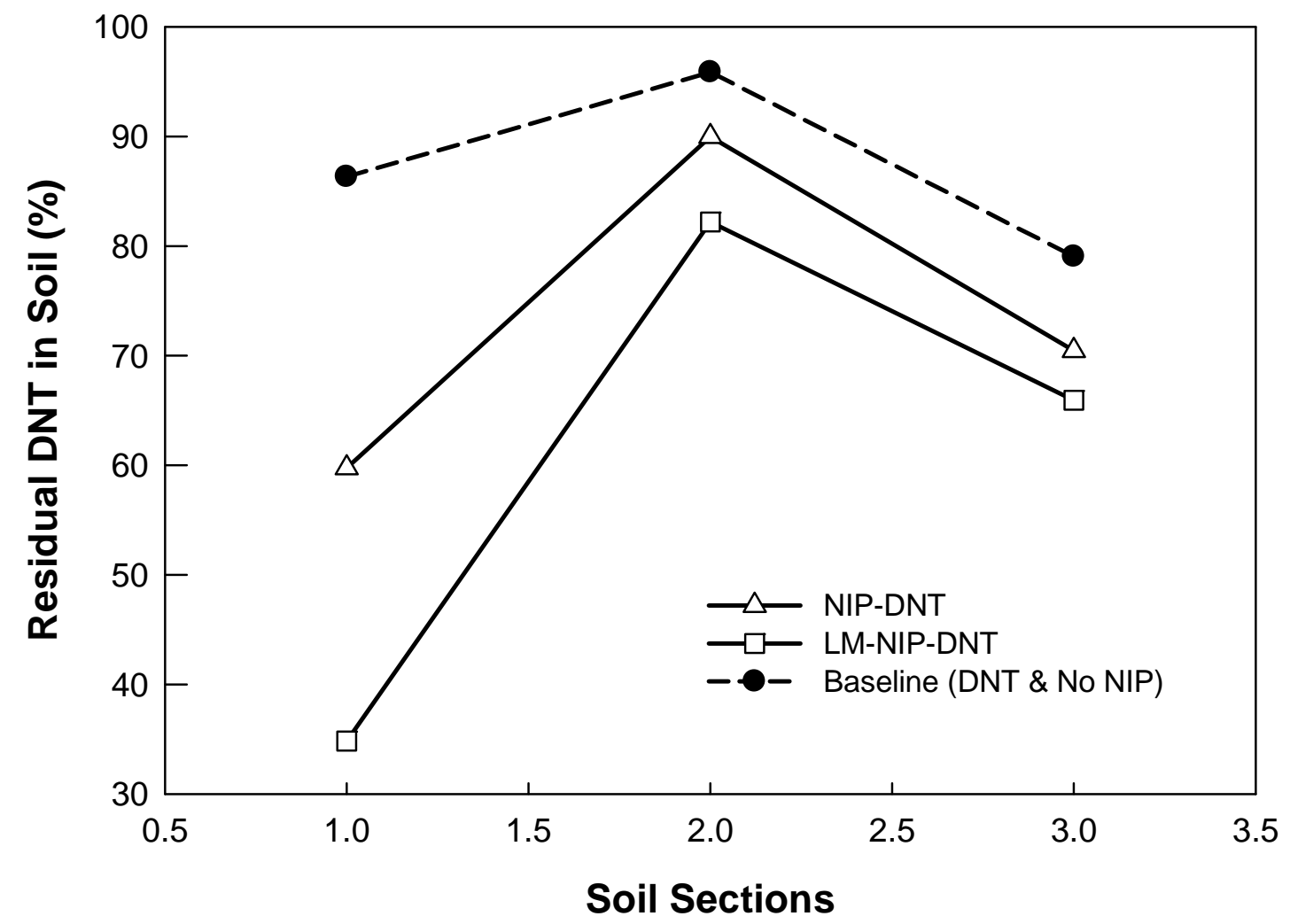

3
4
5
6
7 